\title{
Short-term trends in the prevalence, awareness, treatment, and control of arterial hypertension in Peru
}

\author{
David Villarreal-Zegarra $\mathbb{( I}^{1} \cdot$ Rodrigo M. Carrillo-Larco ${ }^{1,2,3} \cdot$ Antonio Bernabe-Ortiz $\mathbb{D}^{1,4}$
}

Received: 5 February 2020 / Revised: 11 May 2020 / Accepted: 28 May 2020 / Published online: 9 June 2020

(c) The Author(s) 2020. This article is published with open access

\begin{abstract}
The prevalence of hypertension has been declining in low- and middle-income countries (LMIC), particularly in Latin America and the Caribbean. However, we have not identified studies that evaluate trends for awareness, treatment, and control of hypertension in LMIC. We aimed to describe the trends in the prevalence, awareness, treatment, and control of hypertension in Peru. A cross-sectional analysis was conducted using secondary data (4 years) of the Demographic and Health Survey of Peru (ENDES, Spanish acronym), which is conducted annually and is representative at the country level. The age-standardized prevalence was estimated using the World Health Organization population as the reference population. The trend over time was evaluated with the score test for trend of odds. A total of 109,401 participants were included. In Peru, from 2015 to 2018, the age-standardized prevalence of hypertension increased $(p<0.001)$, while the proportion of people with disease awareness $(p<0.001)$ and controlled hypertension decreased $(p=0.01)$. During that same period, the proportion of people with treatment for hypertension did not vary over time $(p=0.13)$. In 2018 , the age-standardized prevalence of hypertension was $20.6 \%$, and the proportion of people with disease awareness, treatment, and control of arterial hypertension was $43.5 \%, 20.6 \%, 5.3 \%$, respectively. People with low socioeconomic status and people living in rural areas have the lowest proportion of awareness, treatment, and control of hypertension.
\end{abstract}

\section{Background}

Hypertension is one of the most important risk factors for different cardiovascular diseases [1]. Providing greater access to treatment and developing policies to treat hypertension has proven to be a cost-effective intervention that would reduce the number of deaths due to cardiovascular diseases and a large number of cardiovascular problems [2].

Supplementary information The online version of this article (https:// doi.org/10.1038/s41371-020-0361-1) contains supplementary material, which is available to authorized users.

Antonio Bernabe-Ortiz

antonio.bernabe@upch.pe

1 CRONICAS Center of Excellence in Chronic Diseases, Universidad Peruana Cayetano Heredia, Lima, Peru

2 Department of Epidemiology and Biostatistics, School of Public Health, Imperial College London, London, UK

3 Instituto de Investigación, Universidad Católica de Trujillo, Chimbote, Peru

4 Universidad Científica del Sur, Lima, Peru
In particular, $\sim 80 \%$ of all deaths in low- and middle-income countries (LMIC) are due to cardiovascular disease [3].

The prevalence of hypertension is around 22\% in LMIC; however, only $43.6 \%$ of the cases are aware of having this condition, $36.9 \%$ receive appropriate treatment, yet only 9.9\% are controlled [4]. The prevalence of high blood pressure has been declining in LMIC, particularly in Latin America and the Caribbean [5]. However, we have not identified studies that evaluate trends for awareness, treatment, and control of hypertension in LMIC.

Identifying current trends and distributions of awareness, treatment, and control of hypertension will allow a better allocation of resources, including relevant policies and interventions in LMIC. A study identified that in 12 highincome countries, the awareness, treatment, and control of hypertension improved substantially, and the prevalence of hypertension reduced [6]. One potential reason for this is that high-income countries have higher health budgets and have implemented programs from chronic disease detection and control $[6,7]$.

The use of trend analysis methodology to measure changes in prevalence, awareness, treatment, and control of hypertension at the national level was originally done using 
the National Health and Nutrition Examination Survey [8]. Currently, other studies have used the same methodology to test this aim in different countries as these three indicators (i.e., awareness, treatment, and control) vary according to the characteristics of each country. National studies in China and Korea suggest that these measures are trending upward in all areas $[9,10]$. In comparison, a national study in Chile suggests that the percentage of people with disease awareness remains stable over time, but the percentage of people with treatment and control have increased [11]. In Mexico, awareness, treatment, and control have all stabilized [12]. Further work to identify trends over time will allow a more complete assessment of whether national health systems are improving access to health. Therefore, we aimed to describe the short-term trends in the prevalence, awareness, treatment, and control of hypertension in Peru.

\section{Methods}

\section{Study design}

Data from the National Demographic and Health Survey of Peru (ENDES-Spanish acronym), which collects information on several variables including poverty, fertility, violence, and health, was utilized in this study. Our study, therefore, decided to use data collected by ENDES over these 4 years (between the years 2015 and 2018).

\section{Study population and selection criteria}

The sampling used a bietapic approach. In rural areas, the primary sampling units consisted of clusters of 500-2000 individuals, and the secondary sampling units were households within each of these clusters. In urban areas, the sampling units consisted of blocks or groups of blocks with more than 2000 individuals and an average of 140 households, and secondary sampling units consisted of households as in rural settings [13]. Details on the sampling process can be found in the technical documents of the ENDES [14]. This study only included participants with complete blood pressure measurements (systolic and diastolic) and information on sociodemographic variables of interest (sex, age, area, economic level, year of evaluation, and region of origin).

\section{Procedures}

\section{Data collection process}

Blood pressure levels were collected using a digital tensiometer (OMRON, model HEM-713). Two types of cuffs were used, depending on the arm circumference of the participants: standard arm $(220-320 \mathrm{~mm})$ and thicker arm $(330-430 \mathrm{~mm})$. The blood pressure measurements were evaluated twice with the participant sitting and their right arm resting on a flat surface at the heart level. The first measurement was taken after a rest period of 5 min, and the second measurement was taken 2 min after the first measurement [15]. In addition, ENDES collected self-reported information about whether the participant had a previous diagnosis of hypertension, received antihypertensive medication, and other sociodemographic data.

\section{Assessment of consistency and plausibility of measurements}

To ensure that only plausible blood pressure measurements were included in the analysis, a cut-off point was used as in pooled studies [5]: systolic blood pressure (SBP) measurements should be $\leq 270 \mathrm{mmHg}$ and $\geq 70 \mathrm{mmHg}$; and the diastolic blood pressure (DBP) measurements should be $\leq 150 \mathrm{mmHg}$ and $\geq 50 \mathrm{mmHg}$ [5]. The no-plausible measures were dropped from analyses.

We defined three criteria to ascertain the consistency between the two blood pressure measurements. First, if the difference between the two measures of SBP (or DBP) was $\leq 5 \mathrm{mmHg}$, both measures were averaged. Second, if the difference between two of the SBP (or DBP) measurements was $\geq 6 \mathrm{mmHg}$, only the second blood pressure measurement was used, provided that the first measurement was greater than the second. This criterion arises because the evidence indicates that the first measurement is often greater than the second because of the white coat effect [16]. Third, if the difference between the two measurements of SBP (or BPD) was $\geq 6 \mathrm{mmHg}$, and the second measure was greater than the first, this observation was excluded from the analysis. We use this criterion because in epidemiological studies the first measurement tends to be greater than the second measurement of blood pressure [16, 17].

\section{Variables}

\section{Hypertension}

Hypertension was defined as those having $\mathrm{SBP} \geq 140$ $\mathrm{mmHg}$ or $\mathrm{DBP} \geq 90 \mathrm{mmHg}$, or having a previous selfreported diagnosis of hypertension.

\section{Hypertensive patients with disease awareness}

Participants aware of hypertension were those who reported having received a previous diagnosis of hypertension. 


\section{Hypertensive patients with treatment}

Participants aware of their hypertension status, and that selfreported taking appropriate antihypertensive medication.

\section{Controlled hypertension}

Participants aware of their hypertension status, that selfreported taking appropriate antihypertensive medication, and has normal blood pressure values $(\mathrm{SBP}<140 \mathrm{mmHg}$ and $\mathrm{DBP}<90 \mathrm{mmHg}$ ).

\section{Other variables}

In addition, a set of sociodemographic variables were also considered. The socioeconomic status (SES) was defined in quintiles (very low, low, middle, high, and very high) based on a wealth index available in the ENDES [18]. This index was calculated based on assets and services that the participant reports having in their household. The calculation of this index can be consulted in the DHS Report [18]. Age, as a continuous variable, was split into groups of 10 years (15-24, 25-34, 35-44, 45-54, 55-64, 65-74, and 75 to more). The sex (male vs. female), study area (urban/rural), and year of ENDES evaluation were also included.

\section{Statistical methods}

All statistical analyses were performed using Stata 13 (StataCorp, College Station, TX, USA) and the graphics were elaborated using the ggplot libraries in R (version 3. 5. 1) and QGIS v2.18. The number and percentage of participants dropped from analyses were reported. The analysis was performed for each year of measurement. The agestandardized prevalence was calculated taking as a reference from the population of the World Health Organization [19]. All the analyses took into account the weighting by

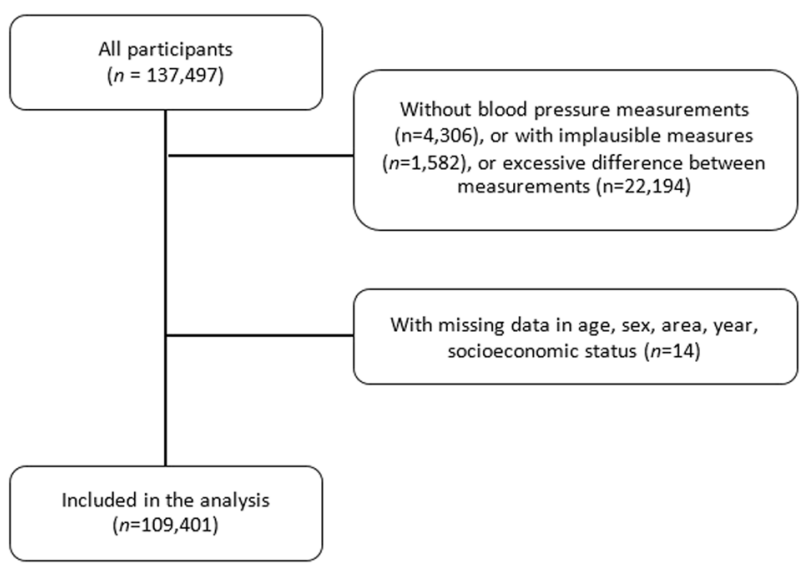

Fig. 1 Flowchart of the participants included in our study. $\mathrm{n}$ number of participants. complex sampling, and the "svy subpop" command was used for subgroup analyses [20]. The 95\% confidence interval $(95 \% \mathrm{CI})$ was calculated for the regional and national measures. The trend over time was evaluated with the score test for trend using the year 2015 as the reference category.

A sub-analysis was performed considering the cut-points recommended by the guidelines of the American College of Cardiology/American Heart Association (ACC/AHA) in 2017, where hypertension was defined as those with $\mathrm{SBP} \geq$ $130 \mathrm{mmHg}$ or DBP $\geq 80 \mathrm{mmHg}$ [21].

\section{Results}

\section{Participants}

From 2015 to 2018 a total of 137,497 individuals were evaluated in the ENDES. After applying the inclusion criteria of the study, 109,401 participants were included (see Fig. 1) and 28,096 participants were dropped (17.4\% of the total, see Supplementary 1). The ages of the participants ranged between 15 and 98 years and the average age was 40.5 (SD: 16.7). Most of the participants were women $(51.3 \%)$, were between 15 and 34 years old (43.4\%), and lived in urban areas $(72.6 \%)$. The characteristics of the participants included per year of evaluation can be seen in Table 1.

\section{Prevalence of hypertension}

The age-standardized prevalence of hypertension increased from $18.7 \%$ to $20.6 \%$ between 2015 and 2018 (score test for trend: $p$ value $<0.001)$. Adults older than 75 years were the age group with the highest age-standardized prevalence (65.5\% in 2018). Men (18.6\% in 2015 to $22.4 \%$ in 2018) had a higher age-standardized prevalence compared to women (18.8\% in 2015 and 2018). The age-standardized prevalence increased most in individuals with low SES (18.7\% in 2015 to $21.9 \%$ ) and meager SES (15.3\% in 2015 to $16.0 \%$ in 2018). Age-standardized prevalence of hypertension (in 2018) was higher in the jungle and southern coastal provinces. The distribution by region can be seen in Fig. 2a.

\section{Hypertensive patients with disease awareness}

Among participants with hypertension, the proportion of people aware of their condition reduced from $53.4 \%$ in 2015 to $43.5 \%$ in 2018 (score test for trend: $p$ value $<$ 0.001). A higher proportion of hypertensive individuals aware of their condition were women, and the proportion increased with age (see Table 2). In five of the 25 regions of 
Table 1 Descriptive characteristics of the participants included in the study.

\begin{tabular}{|c|c|c|c|c|c|c|c|c|}
\hline & \multicolumn{2}{|l|}{2015} & \multicolumn{2}{|l|}{2016} & \multicolumn{2}{|l|}{2017} & \multicolumn{2}{|l|}{2018} \\
\hline & $n$ & $\%$ & $n$ & $\%$ & $n$ & $\%$ & $n$ & $\%$ \\
\hline \multicolumn{9}{|l|}{ Sex } \\
\hline Male & 12,217 & $48.9 \%$ & 11,680 & $49.1 \%$ & 11,811 & $48.4 \%$ & 12,004 & $48.3 \%$ \\
\hline Female & 15,195 & $51.1 \%$ & 15,000 & $50.9 \%$ & 15,331 & $51.6 \%$ & 16,163 & $51.7 \%$ \\
\hline \multicolumn{9}{|l|}{ Age } \\
\hline $15-24$ & 5,616 & $24.1 \%$ & 5,295 & $23.4 \%$ & 5,222 & $22.3 \%$ & 5,228 & $21.4 \%$ \\
\hline $25-34$ & 7,894 & $20.5 \%$ & 7,394 & $20.5 \%$ & 7,609 & $20.7 \%$ & 7,847 & $20.7 \%$ \\
\hline $35-44$ & 5,757 & $18.5 \%$ & 5,630 & $18.6 \%$ & 5,611 & $19.5 \%$ & 6,196 & $19.4 \%$ \\
\hline $45-54$ & 3,190 & $15.1 \%$ & 3,242 & $15.2 \%$ & 3,288 & $15.3 \%$ & 3,355 & $15.3 \%$ \\
\hline $55-64$ & 2,362 & $10.1 \%$ & 2,408 & $10.4 \%$ & 2,467 & $10.3 \%$ & 2,646 & $10.9 \%$ \\
\hline $65-74$ & 1,576 & $6.7 \%$ & 1,588 & $6.7 \%$ & 1,732 & $6.9 \%$ & 1,793 & $7.1 \%$ \\
\hline $75+$ & 1,017 & $5.1 \%$ & 1,123 & $5.1 \%$ & 1,213 & $5.0 \%$ & 1,102 & $5.2 \%$ \\
\hline \multicolumn{9}{|l|}{ Area } \\
\hline Urban & 17,998 & $65.5 \%$ & 17,545 & $64.8 \%$ & 17,925 & $79.5 \%$ & 18,476 & $80.4 \%$ \\
\hline Rural & 9,414 & $34.6 \%$ & 9,135 & $35.2 \%$ & 9,217 & $20.5 \%$ & 9,691 & $19.6 \%$ \\
\hline \multicolumn{9}{|l|}{ SES } \\
\hline Very low & 7,668 & $26.2 \%$ & 7,369 & $26.3 \%$ & 8,139 & $18.3 \%$ & 8,955 & $18.7 \%$ \\
\hline Low & 6,883 & $21.3 \%$ & 7,005 & $22.2 \%$ & 6,988 & $20.7 \%$ & 6,979 & $20.8 \%$ \\
\hline Middle & 5,304 & $18.3 \%$ & 5,243 & $18.5 \%$ & 5,238 & $21.0 \%$ & 5,232 & $20.7 \%$ \\
\hline High & 4,180 & $17.9 \%$ & 4,188 & $17.4 \%$ & 3,974 & $20.3 \%$ & 3,991 & $20.3 \%$ \\
\hline Very high & 3,377 & $16.3 \%$ & 2,875 & $15.7 \%$ & 2,803 & $19.8 \%$ & 3,010 & $19.5 \%$ \\
\hline \multicolumn{9}{|l|}{ Hypertension $^{\mathrm{a}}$} \\
\hline Yes & 4,563 & $18.7 \%$ & 4,445 & $18.5 \%$ & 4,590 & $19.4 \%$ & 5,168 & $20.6 \%$ \\
\hline No & 22,849 & $81.3 \%$ & 22,235 & $81.5 \%$ & 22,552 & $80.6 \%$ & 22,999 & $79.4 \%$ \\
\hline
\end{tabular}

The weighted proportion by complex sampling.

SES socioeconomic status.

${ }^{\mathrm{a}}$ Age-standarized prevalence.
Peru, the proportion of people who are aware of their disease was less than 50\% (see Fig. 2b).

When using the ACC/AHA recommended cut-off point, the percentage of individuals aware of their hypertension decreased by $12.8 \%$ (see Supplementary 2).

\section{Hypertensive patients with treatment}

When analyzing only patients with hypertension, one in five people with hypertension in Peru reported receiving treatment, and no significant trend was found between 2015 and 2018 (score test for trend: $p$ value $=0.13$, see Fig. 3). In a sub-analysis considering only hypertensive patients with disease awareness, the proportion of those receiving treatment did not change between 2015 and 2018 (36.7\% to $42.7 \%$, respectively; score test for trend: $p$ value $=0.10$ ). Hypertensive individuals with a high socioeconomic level and older adults had the highest proportion of treatment (see Table 2). The regions located in the Southeastern area of Peru had the lowest proportion of treatment (see Fig. 2c).

\section{Controlled hypertension}

In Peru, only one out of every 20 people with hypertension had their blood pressure controlled, and there was a negative trend over time (score test for trend, $p$ value $=$ 0.01). When performing a sub-analysis in only the people receiving treatment, the proportion of people with controlled hypertension varied between $42.1 \%$ (2015) and $35.4 \%$ (2018; score test for trend, $p$ value $=0.03$ ). Men, adolescents, young, and people with a very low economic status with hypertension had the poorest control (see Table 2). Only in three of the 25 regions of Peru, the proportion of patients with controlled hypertension was greater than $10 \%$ (see Fig. 2d).

When utilizing the ACC/AHA recommended cut-off point, it halved the proportion of controlled hypertensives (see Supplementary 2).

\section{Discussion}

\section{Main findings}

In Peru, from 2015 to 2018, the age-standardized prevalence of hypertension increased, while the proportion of people with disease awareness and controlled hypertension decreased. During that same period, the proportion of people with treatment for hypertension did not vary over time. 
Fig. 2 Age-standardized prevalence of hypertension, and the proportion of hypertensive patients with disease awareness and treatment and control by region in 2018. a Agestandardized prevalence of hypertension in Peru in 2018. b The proportion of hypertensive patients with disease awareness in Peru in 2018. c The proportion of hypertensive patients with treatment in Peru in 2018. d The proportion of patients with controlled hypertension in Peru in 2018.
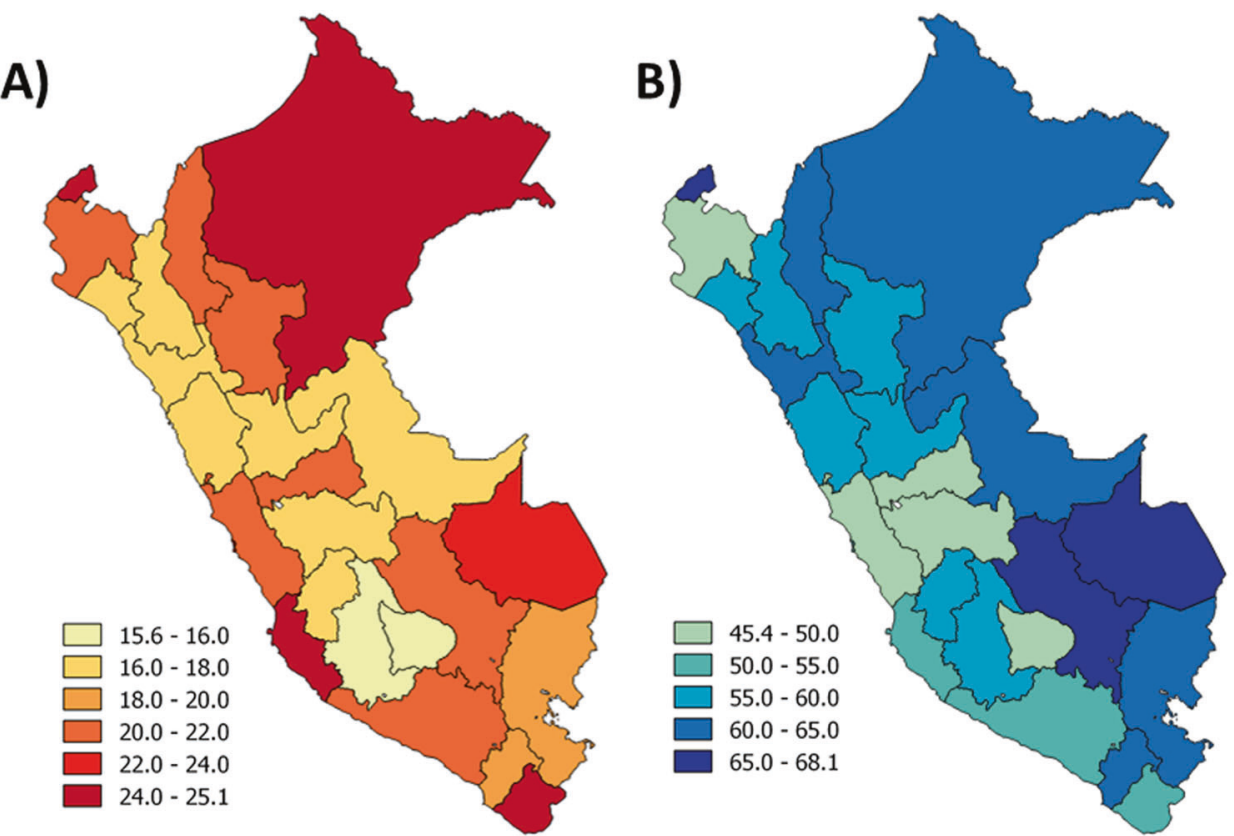

Age-standardized prevalence of hypertension

c)

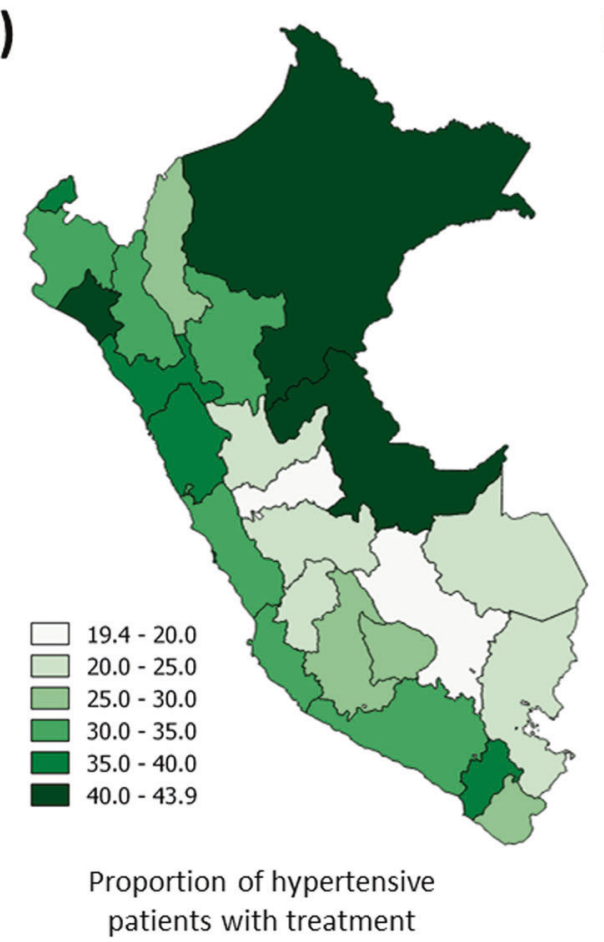

Proportion of hypertensive patients with disease awareness

D)

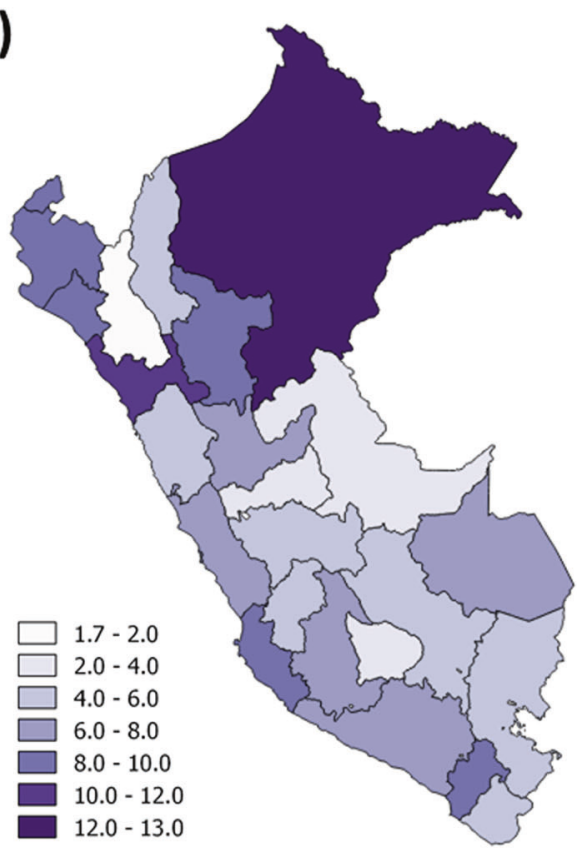

Proportion of patients with controlled hypertension.
People with low SES and people living in rural areas have the lowest proportion of awareness, treatment, and control of hypertension. Approximately one in five people in Peru have hypertension. This high prevalence coupled with low rates of awareness, treatment, and control of hypertension as well as the deep socioeconomic inequalities throughout the country, constitute a public health problem in Peru.

\section{Comparison with previous studies}

\section{Prevalence}

The high blood pressure is decreasing across the LMIC [5], and the prevalence of hypertension in several high-income countries [6]. However, the political and health conditions 
Table 2 Proportion of Peruvian hypertensive patients with disease awareness, treatment, and controlled hypertension by sociodemographic characteristics (2015-2018).

\begin{tabular}{|c|c|c|c|c|c|c|c|c|c|}
\hline & 2015 & 2016 & 2017 & 2018 & Area & & & & \\
\hline \multirow{2}{*}{\multicolumn{5}{|c|}{ Hypertensive patients with disease awareness }} & Urban & $8.9 \%$ & $8.2 \%$ & $8.0 \%$ & $7.2 \%$ \\
\hline & & & & & Rural & $7.9 \%$ & $7.5 \%$ & $6.3 \%$ & $6.2 \%$ \\
\hline \multicolumn{5}{|l|}{ Sex } & \multicolumn{5}{|l|}{ SES } \\
\hline Male & $45.3 \%$ & $41.9 \%$ & $37.9 \%$ & $38.6 \%$ & Very low & $7.1 \%$ & $6.3 \%$ & $6.6 \%$ & $4.8 \%$ \\
\hline Female & $73.7 \%$ & $69.2 \%$ & $67.6 \%$ & $70.5 \%$ & Low & $7.6 \%$ & $8.4 \%$ & $6.9 \%$ & $6.2 \%$ \\
\hline \multicolumn{5}{|l|}{ Age } & Middle & $7.2 \%$ & $6.0 \%$ & $8.9 \%$ & $6.2 \%$ \\
\hline $15-24$ & $43.1 \%$ & $27.4 \%$ & $37.4 \%$ & $33.6 \%$ & High & $11.1 \%$ & $7.8 \%$ & $6.1 \%$ & $7.3 \%$ \\
\hline $25-34$ & $47.3 \%$ & $35.7 \%$ & $42.5 \%$ & $33.4 \%$ & Very high & $9.7 \%$ & $11.7 \%$ & $9.6 \%$ & $9.8 \%$ \\
\hline
\end{tabular}

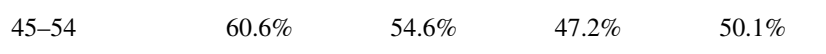

\begin{tabular}{|c|c|c|}
\hline $55-64$ & $62.4 \%$ & \\
\hline
\end{tabular}

\begin{tabular}{|c|c|}
\hline $65-74$ & \\
\hline
\end{tabular}

$\begin{array}{lllll}75+ & 66.2 \% & 64.1 \% & 62.6 \% & 69.3 \%\end{array}$

Area

\begin{tabular}{|c|c|c|c|}
\hline Urban & $62.6 \%$ & $56.0 \%$ & $53.1 \%$ \\
\hline
\end{tabular}

$\begin{array}{lllll}\begin{array}{l}\text { Rural } \\ \text { SES }\end{array} & 54.1 \% & 53.1 \% & 49.8 \% & 54.0 \% \\ \text { Very low } & 50.4 \% & 48.0 \% & 46.5 \% & 51.2 \% \\ \text { Low } & 58.0 \% & 56.6 \% & 52.9 \% & 52.2 \% \\ \text { Middle } & 58.0 \% & 58.8 \% & 57.7 \% & 52.5 \% \\ \text { High } & 65.9 \% & 53.8 \% & 50.8 \% & 55.7 \% \\ \text { Very high } & 68.0 \% & 60.5 \% & 54.0 \% & 57.0 \%\end{array}$

Hypertensive patients with treatment Sex

\begin{tabular}{|c|c|c|c|c|}
\hline \multicolumn{5}{|l|}{ sex } \\
\hline Male & $24.9 \%$ & $26.0 \%$ & $21.4 \%$ & $23.4 \%$ \\
\hline Female & $44.0 \%$ & $41.3 \%$ & $41.6 \%$ & $44.2 \%$ \\
\hline \multicolumn{5}{|l|}{ Age } \\
\hline $15-24$ & $4.9 \%$ & $6.2 \%$ & $4.7 \%$ & $8.5 \%$ \\
\hline $25-34$ & $9.5 \%$ & $11.7 \%$ & $11.7 \%$ & $10.6 \%$ \\
\hline $35-44$ & $22.1 \%$ & $20.2 \%$ & $17.6 \%$ & $18.0 \%$ \\
\hline $45-54$ & $28.3 \%$ & $28.0 \%$ & $23.7 \%$ & $26.0 \%$ \\
\hline $55-64$ & $40.8 \%$ & $34.3 \%$ & $33.9 \%$ & $36.8 \%$ \\
\hline $65-74$ & $44.6 \%$ & $46.3 \%$ & $41.2 \%$ & $47.8 \%$ \\
\hline $75+$ & $52.6 \%$ & $49.6 \%$ & $52.3 \%$ & $52.6 \%$ \\
\hline \multicolumn{5}{|l|}{ Area } \\
\hline Urban & $38.2 \%$ & $35.6 \%$ & $32.4 \%$ & $34.7 \%$ \\
\hline Rural & $26.9 \%$ & $28.6 \%$ & $26.5 \%$ & $26.8 \%$ \\
\hline \multicolumn{5}{|l|}{ SES } \\
\hline Very low & $24.3 \%$ & $23.0 \%$ & $25.7 \%$ & $24.9 \%$ \\
\hline Low & $29.9 \%$ & $32.6 \%$ & $26.5 \%$ & $26.2 \%$ \\
\hline Middle & $30.3 \%$ & $34.1 \%$ & $34.0 \%$ & $29.2 \%$ \\
\hline High & $44.0 \%$ & $33.7 \%$ & $28.7 \%$ & $39.7 \%$ \\
\hline Very high & $45.1 \%$ & $46.2 \%$ & $38.7 \%$ & $43.2 \%$ \\
\hline \multicolumn{5}{|c|}{ Controlled hypertension } \\
\hline \multicolumn{5}{|l|}{ Sex } \\
\hline Male & $6.2 \%$ & $5.8 \%$ & $4.8 \%$ & $3.4 \%$ \\
\hline Female & $10.8 \%$ & $10.3 \%$ & $10.7 \%$ & $10.9 \%$ \\
\hline \multicolumn{5}{|l|}{ Age } \\
\hline $15-24$ & $3.6 \%$ & $2.0 \%$ & $3.1 \%$ & $3.9 \%$ \\
\hline $25-34$ & $4.5 \%$ & $4.7 \%$ & $4.9 \%$ & $3.5 \%$ \\
\hline $35-44$ & $6.1 \%$ & $7.4 \%$ & $4.4 \%$ & $4.2 \%$ \\
\hline $45-54$ & $7.1 \%$ & $9.5 \%$ & $6.9 \%$ & $5.5 \%$ \\
\hline $55-64$ & $12.4 \%$ & $7.9 \%$ & $9.3 \%$ & $8.7 \%$ \\
\hline $65-74$ & $10.6 \%$ & $9.6 \%$ & $7.9 \%$ & $10.3 \%$ \\
\hline $75+$ & $8.9 \%$ & $8.0 \%$ & $11.7 \%$ & $7.9 \%$ \\
\hline
\end{tabular}

of each country are very heterogeneous, making countrylevel evaluations necessary. Some countries, such as China [11] and Chile [22], are reporting a trend of an increase in the prevalence of hypertension. In other places, such as Portugal, hypertension is becoming less common and has a downward trend [23]. However, most studies indicate that in other places, hypertension prevalence remains stable over time such as in Italy [24], Mexico [12], Brazil [25], and USA [26].

The differences between national-level estimates (i.e. including only one country) and global trends of several countries may be due to different reasons. First, global trends studies consider a greater amount of time (40 years) [6] compared to the country-level studies (between 5 and 15 years). Second, country-level studies use different methodologies to assess blood pressure. Therefore, it does not allow some studies to be directly compared. When evaluating the age-standardized prevalence of hypertension in Peru in 2018, this estimate was similar to other studies recently published in Peru (19.2\% to $19.7 \%)$ 
$[27,28]$; nevertheless, the prevalence of hypertension is slightly lower than the average of the LMIC (22\%) [4].

The increased hypertension prevalence could be since Peru has experienced a continuous economic growth in recent years and is gradually catching up with the prosperity of other countries in the region. This situation could cause the population to experience an epidemiological transition, as they would be prone to participate in risk behaviors (i.e., smoking, obesity, sedentary) as they would have higher incomes [29]. Our data reinforces this hypothesis since people of lower SES are those who show a greater increase in the age-standardized prevalence of hypertension.

\section{Awareness, treatment, and control}

When comparing our findings with other similar studies, LMIC present heterogeneous realities. In Latin America, a representative study for Chile (1988-2004) suggests that the percentage of people with disease awareness remains stable over time, but the percentage of people with treatment and control has increased [22]; in Mexico between 2000 and 2012, awareness, treatment, and control are not changing [12]. On the other hand, in Asia, national studies in China (1982-2010) and Korea (2007-2011) suggest that awareness, treatment, and control are increasing [9, 10]. This heterogeneity may be due to the different political conditions and the percentage of resources in the health system of the LMIC.

Decreasing awareness may be explained by the disarticulation of health strategies to detect new cases of hypertension as the Peruvian health system is fragmented [30]. In Peru, all primary care facilities offer free blood pressure screenings but in a passive approach. So, there is a need of increasing the number of activities where health workers search people in the community for blood pressure assessments. Also, educational programs that provide information about the effects of hypertension and the importance of its assessment are needed. There is evidence to show that educational programs in community settings enhance the proportion of hypertensive people mindful of their condition [31]. On the other hand, Peru is experiencing an epidemiological transition that increases the amount of cases of individuals with chronic conditions, which would obligate the health system to detect and treat more users than in the capacity to deal. The Peruvian health system is overburdened by different factors, including limited health personnel and medical equipment [30]. Another reason for the reduction in the proportion of awareness hypertensive is socioeconomic factors, as many poor people cannot afford to invest several hours (for one or several days) to receive medical appointments, attend consultations and follow-ups. That is consistent with our data as people living in rural areas and the poorest have a lower proportion of awareness of their hypertension.

The limited availability of medicines prescribed to hypertensive cases and the out-of-pocket costs associated with the specific treatment [32], could explain the reduction in the rate of controlled hypertension. The poorest would have greater problems accessing treatment because medications may be costly or unavailable within the health system. Economic factors may explain why the Southeastern provinces of Peru have a lower rate of hypertensive with treatment, as they are poorer compared to the coastal regions. Another potential reason for the low proportion of controlled hypertension would be beliefs about hypertension and the lack of knowledge of patients about the health complications presented by the lack of treatment [33]. Some patients discontinue treatment when they feel they have improved (no symptoms) or use irregularly the medicines based on the occurrence of symptoms [33].

The ACC/AHA 2017 clinical practice guidelines recommend lower cut-off points to diagnose hypertension (SBP $\geq 130 \mathrm{mmHg}$ or $\mathrm{DBP} \geq 80 \mathrm{mmHg}$ ) [21]. The new cutoff would double the age-standardized prevalence of hypertension in Peru as previously showed [34]. Again, this change in a cut-off of hypertension would reduce the percentage of individuals aware, treated, and controlled in Peru, emphasizing the need for proper health strategies to improve these indicators at the population level. The ACC/ AHA 2017 clinical practice guidelines recommend the use of indexes to estimate the risk of cardiovascular disease as a fundamental factor in the clinical environment and to guide treatment, particularly in older patients [35]. However, a Peruvian study identified little concordance between different indexes of cardiovascular disease risk (AHA/ACC, Framingham risk score for CVD, Reynolds risk score, systematic coronary risk evaluation, World Health Organization risk charts) [36]. As a result, there is uncertainty in choosing any of them to apply within the Peruvian public health system.

The proportion of awareness, treatment, and control of hypertension vary significantly among LMIC, and data regarding hypertension epidemiology in LMIC are scarce compared to high-income countries. This may be due to factors such as investment in health and the ability to manage health resources, as not all LMIC allocate a sufficient proportion of their resources in health or optimally manage their resources [37]. The World Health Organization proposes that $6 \%$ of the gross domestic product be destined for health, but not all LMIC comply with this recommendation, as is the case in Peru [37, 38]. Also, social factors such as poverty, low education of the population, and cultural elements likely also influence hypertension awareness, treatment, and control. Studies support that poverty and inequality in the distribution of 
resources are some of the main barriers to accessing medical care [39].

Our study presented differences with other studies conducted in Peru on awareness, treatment, and control in hypertensive people. A study conducted throughout Peru identified similar values of people aware of having hypertension (48.2\%). However, the values for people with hypertension who are treated $(39.3 \%)$ and are controlled $(20.6 \%)$ were higher [40]. Another study conducted in three Peruvian cities (urban and rural) also found higher values for both awareness (69\%, 95\% CI 64.4-73.5\%), selfreported treatment $(63.2 \%, 95 \%$ CI 58.6-67.8\%) and control $(45.9 \%, 95 \%$ CI 40.9-50.8\%) [27]. On the other hand, another study conducted in three Peruvian cities with migrants and non-migrants identified values similar to those reported in our study for awareness (48.3\%), treatment $(16.6 \%)$, and control of hypertension (4.9\%) [41]. These differences may be due to different methodologies or heterogeneous populations. Nonetheless, our results provide a better picture and stronger results to inform policies and interventions because we have benefitted from a national sample and data over 4 years.

\section{Relevant in public health}

Health policies and interventions must be established to reduce the prevalence and increase the proportion of awareness, treatment, and control of hypertension since it is a public health problem for Peru.

First, strengthen national strategies for screening and diagnosis of hypertension. It is necessary to increase the proportion of hypertensive people with disease awareness because awareness is a basic condition for receiving treatment and achieving blood pressure control. It is suggested that these strategies should have an emotional support component for newly diagnosed people, because there is evidence that people who receive a diagnosis of hypertension are twice as likely to have depressive symptoms, compared to people without hypertension or hypertension without awareness of the disease [42]. Second, to develop decentralized strategies for the care and diagnosis of hypertension cases and to actively involve the community. Evidence suggests active involvement of local communities improves the outcomes of hypertensive patient management and their control of hypertension [43]. Third, establish a surveillance system to identify people with hypertension and send them regular reminders (e.g. text messages) to improve their monitoring and treatment. These interventions are more effective for treatment adherence than attending primary care within the health system [44]. Fourth, establish periodic surveillance of the prevalence, awareness, treatment, and control of hypertension to evaluate the effect of implemented strategies.

\section{Strengths and limitations}

The present study was carried out in a nationally representative sample of the Peruvian population. However, this study has limitations. First, the international guidelines suggest three blood pressure measurements and discard the first due to the white coat effect [16]. Because we have only two blood pressure measurements, results may be altered. Therefore, a set of criteria was used to assess the plausibility of blood pressure measurements, based on evaluating the difference between the two measurements and identifying measurements with less than $\leq 5 \mathrm{mmHg}$ between them. Second, the criteria used in our study to assess the plausibility of the measurements may alter the trend results (our study used a mixed three-step criterion). To evaluate this possibility, three additional analyses were performed where trends were evaluated using a criterion where the difference between the two SBP measurements and the two BPD measurements was $\leq 5 \mathrm{mmHg}, \leq 10 \mathrm{mmHg}$, and $\leq 15 \mathrm{mmHg}$. These three analyses were consistent and did not change our main trend results. Therefore, we do not consider the criterion used to assess the plausibility of the data to be a factor that could be modifying the results. Third, the evaluation time may be insufficient to identify a clear trend, and for instance, further longer surveillance is needed. Finally, other relevant variables that could support a further understanding of the results were not applicable. So, information on treatment adherence, the treatment received, secondary forms of hypertension (i.e., primary aldosteronism, Cushing Syndrome, Pheochromocytoma), and other sociodemographic variables (i.e., ethnic background) was not included in the analyses as they were not available.

\section{Conclusions}

In Peru, between 2015 and 2018, a sustained increase over time in age-standardized prevalence, a reduction in the proportion of people aware and with controlled hypertension was identified. The proportion of individuals with hypertension under treatment remained stable during this period (4 years).

\section{Summary}

\section{What is known about the topic}

- The prevalence of high blood pressure has been declining in low- and middle-income countries (LMIC), particularly in Latin America and the Caribbean.

- There are limited studies evaluating trends for awareness, treatment, and control of hypertension in LMICs. 
- Different national studies carried out in LMIC identify heterogeneity in the trends of knowledge, treatment, and control of hypertension.

\section{What this study adds}

- An increase in hypertension prevalence and a reduction in awareness and control of hypertension are identified in Peru.

- People with low socioeconomic status and people living in rural areas have the lowest proportion of awareness, treatment, and control of hypertension.

Acknowledgements The authors are grateful to Helena Gaspar for reviewing the language and style.

Funding This work was supported by the Strategic Award, Wellcome Trust-Imperial College Centre for Global Health Research (100693/Z/ 12/Z), Imperial College London Wellcome Trust Institutional Strategic Support Fund [Global Health Clinical Research Training Fellowship] (294834/Z/16/Z ISSF ICL), and RMC-L are supported by a Wellcome Trust International Training Fellowship (214185/Z/18/Z). The funders had no role in study design, data collection, and analysis, decision to publish, or preparation of the manuscript.

\section{Compliance with ethical standards}

Conflict of interest The authors declare that they have no conflict of interest.

Ethics The data used in our study is freely available to the general public and does not use any personally identifiable information (anonymous), and consequently does not represent an ethical risk for participants. The National Institute of Statistics and Informatics, a Peruvian government organization, is responsible for the annual collection of ENDES data. This institution requested the consent of participants to obtain the information required in the survey. For each person of legal age (18 years old and above), informed consent for the collection of information was taken. In the case of minors (17 years old and below) the request for consent was read to one of their parents or the adult responsible for the minor to allow assessment.

Publisher's note Springer Nature remains neutral with regard to jurisdictional claims in published maps and institutional affiliations.

Open Access This article is licensed under a Creative Commons Attribution 4.0 International License, which permits use, sharing, adaptation, distribution and reproduction in any medium or format, as long as you give appropriate credit to the original author(s) and the source, provide a link to the Creative Commons license, and indicate if changes were made. The images or other third party material in this article are included in the article's Creative Commons license, unless indicated otherwise in a credit line to the material. If material is not included in the article's Creative Commons license and your intended use is not permitted by statutory regulation or exceeds the permitted use, you will need to obtain permission directly from the copyright holder. To view a copy of this license, visit http://creativecommons. org/licenses/by/4.0/.

\section{References}

1. GBD 2016 Disease and Injury Incidence and Prevalence Collaborators. Global, regional, and national incidence, prevalence, and years lived with disability for 328 diseases and injuries for 195 countries, 1990-2016: a systematic analysis for the Global Burden of Disease Study 2016. Lancet. 2017;390:1211-59.

2. Moran AE, Odden MC, Thanataveerat A, Tzong KY, Rasmussen PW, Guzman D, et al. Cost-effectiveness of hypertension therapy according to 2014 guidelines. N Engl J Med. 2015;372:447-55.

3. Lim SS, Vos T, Flaxman AD, Danaei G, Shibuya K, Adair-Rohani $\mathrm{H}$, et al. A comparative risk assessment of burden of disease and injury attributable to 67 risk factors and risk factor clusters in 21 regions, 1990-2010: a systematic analysis for the Global Burden of Disease Study 2010. Lancet. 2012;380:2224-60.

4. Chow CK, Teo KK, Rangarajan S, Islam S, Gupta R, Avezum A, et al. Prevalence, awareness, treatment, and control of hypertension in rural and urban communities in high-, middle-, and lowincome countries. Jama. 2013;310:959-68.

5. NCD Risk Factor Collaboration (NCD-RisC). Worldwide trends in blood pressure from 1975 to 2015: a pooled analysis of 1479 population-based measurement studies with 19.1 million participants. Lancet. 2017;389:37-55.

6. NCD Risk Factor Collaboration (NCD-RisC. Long-term and recent trends in hypertension awareness, treatment, and control in 12 high-income countries: an analysis of 123 nationally representative surveys. Lancet. 2019;394:639-51.

7. Nerenberg KA, Zarnke KB, Leung AA, Dasgupta K, Butalia S, McBrien K, et al. Hypertension Canada's 2018 guidelines for diagnosis, risk assessment, prevention, and treatment of hypertension in adults and children. Can J Cardiol. 2018;34:506-25.

8. Rocella EJ, Burt V, Horan MJ, Cutler J. Changes in hypertension awareness, treatment, and control rates. 20-year trend data. Ann Epidemiol. 1993;3:547-9.

9. Zhao Y, Yan H, Marshall RJ, Dang S, Yang R, Li Q, et al. Trends in population blood pressure and prevalence, awareness, treatment, and control of hypertension among middle-aged and older adults in a rural area of Northwest China from 1982 to 2010. PloS ONE. 2013;8:e61779.

10. Moon JY, Park KJ, Hwangbo Y, Lee MR, Yoo BI, Won JH, et al. A trend analysis of the prevalence, awareness, treatment, and control of hypertension by age group. J Preventive Med Public Health. 2013;46:353.

11. Huang G, Xu JB, Liu Y, Liu ZH, Zhang YL, Wu YL, et al. Temporal trends in prevalence, awareness, treatment, and control of hypertension from 2000 to 2010 in Chengdu, China. Sci Rep. 2017;7:8964

12. Campos-Nonato I, Hernandez-Barrera L, Rojas-Martinez R, Pedroza A, Medina-Garcia C, Barquera-Cervera S. Hypertension: prevalence, early diagnosis, control and trends in Mexican adults. Salud Publica Mex. 2013;55(Suppl 2):S144-50.

13. Instituto Nacional de Estadística e Informática. Perú: encuesta demográfica y de salud familiar ENDES 2014. Perú: Instituto Nacional de Estadística e Informática; 2015.

14. Instituto Nacional de Estadística e Informática. Perú - Encuesta Demográfica y de Salud Familiar ENDES 2017. Peru: Instituto Nacional de Estadística e Informática; 2018.

15. Instituto Nacional de Estadística e Informática. Manual de la entrevistadora - Encuesta demográfica y de salud familiar. Perú: Instituto Nacional de Estadística e Informática; 2018.

16. Gorostidi M, Vinyoles E, Banegas JR, de la Sierra A. Prevalence of white-coat and masked hypertension in national and international registries. Hypertension Res. 2015;38:1-7.

17. Schulze MB, Kroke A, Bergmann MM, Boeing H. Differences of blood pressure estimates between consecutive measurements on 
one occasion: implications for inter-study comparability of epidemiologic studies. Eur J Epidemiol. 2000;16:891-8.

18. Rutstein SO, Johnson K. The DHS wealth index. DHS comparative reports no. 6. Calverton, MD: ORC Macro; 2004.

19. Ahmad OB, Boschi-Pinto C, Lopez AD, Murray CJ, Lozano R, Inoue M. Age standardization of rates: a new who standard, vol. 31. Geneva: World Health Organization; 2001.

20. Saylor J, Friedmann E, Lee HJ. Navigating complex sample analysis using national survey data. Nurs Res. 2012;61:231-7.

21. Whelton PK, Carey RM, Aronow WS, Casey DE, Collins KJ, Dennison Himmelfarb C, et al. 2017 ACC/AHA/AAPA/ABC/ ACPM/AGS/APhA/ASH/ASPC/NMA/PCNA guideline for the prevention, detection, evaluation, and management of high blood pressure in adults: a report of the American College of Cardiology/American Heart Association Task Force on Clinical Practice Guidelines. J Am Coll Cardiol. 2018;71:e127-248.

22. Fasce E, Campos I, Ibanez P, Flores M, Zarate H, Roman O, et al. Trends in prevalence, awareness, treatment, and control of hypertension in urban communities in Chile. J Hypertens. 2007;25:1807-11.

23. Pereira M, Carreira H, Vales C, Rocha V, Azevedo A, Lunet N. Trends in hypertension prevalence (1990-2005) and mean blood pressure (1975-2005) in Portugal: a systematic review. Blood Press. 2012;21:220-6.

24. Tocci G, Muiesan ML, Parati G, Agabiti Rosei E, Ferri C, Virdis A, et al. Trends in prevalence, awareness, treatment, and control of blood pressure recorded From 2004 to 2014 During World Hypertension Day in Italy. J Clin Hypertens. 2016;18:551-6.

25. Andrade SS, Malta DC, Iser BM, Sampaio PC, de Moura L. Prevalence of self-reported arterial hypertension in Brazilian capitals in 2011 and analysis of its trends in the period between 2006 and 2011. Rev Brasileira de epidemiologia = Braz J Epidemiol. 2014;17(Suppl 1):215-26.

26. Guo F, He D, Zhang W, Walton RG. Trends in prevalence, awareness, management, and control of hypertension among United States adults, 1999 to 2010. J Am Coll Cardiol. 2012;60:599-606.

27. Irazola VE, Gutierrez L, Bloomfield G, Carrillo-Larco RM, Dorairaj P, Gaziano T, et al. Hypertension prevalence, awareness, treatment, and control in selected LMIC communities: results from the NHLBI/UHG Network of Centers of Excellence for Chronic Diseases. Glob Heart. 2016;11:47-59.

28. Bernabe-Ortiz A, Carrillo-Larco RM, Gilman RH, Checkley W, Smeeth L, Miranda JJ. Impact of urbanization and altitude on the incidence of, and risk factors for, hypertension. Heart. 2017;103:827-33.

29. Lamelas P, Diaz R, Orlandini A, Avezum A, Oliveira G, Mattos A, et al. Prevalence, awareness, treatment, and control of hypertension in rural and urban communities in Latin American countries. J Hypertens. 2019;37:1813-21.

30. Soto A. Barriers to effective care in the referralhospitals of Peru's Ministry of Health: serving patients in the 21st centurywith 20thcentury resources. Rev Peru Med Exp Salud Publica. 2019;36:304-11.

31. Darrat M, Houlihan A, Gibson I, Rabbitt M, Flaherty G, Sharif F. Outcomes from a community-based hypertension educational program: the West of Ireland Hypertension study. Ir J Med Sci. 2018;187:675-82.

32. Tenorio Mucha JM. Acceso a medicamentos para controlar la hipertensión arterial prescritos en consulta externa en las Instituciones Prestadoras de Servicios de Salud (IPRESS) en Perú, ENSUSALUD 2016. Perú: Maestro en Ciencias en Investigación Epidemiológica, Tesis de maestría, Universidad Peruana Cayetano Heredia; 2019.

33. Ávila-Sansores GM, Gómez-Aguilar P, Yam-Sosa AV, VegaArgote G, Franco-Corona BE. Un enfoque cualitativo a las barreras de adherencia terapéutica en enfermos crónicos de Guanajuato, México. Aquichan. 2013;13:373-86.

34. Hernández-Vásquez A, Rojas-Roque C, Santero M, Ruiz-Maza JC, Casas-Bendezú M, Miranda JJ. Changes in the prevalence of hypertension in Peru using the new guideline of the American College of Cardiology. Rev Med de Chile. 2019;147:545-56.

35. World Health Organization. Prevention of cardiovascular disease: guidelines for assessment and management of cardiovascular risk. Switzerland: World Health Organization; 2007.

36. Bazo-Alvarez JC, Quispe R, Peralta F, Poterico JA, Valle GA, Burroughs $\mathrm{M}$, et al. Agreement between cardiovascular disease risk scores in resource-limited settings: evidence from 5 Peruvian sites. Crit Pathw Cardiol. 2015;14:74-80.

37. World Health Organization. World Health Statistics 2014: a wealth of information on global public health. Geneva: World Health Organization; 2014.

38. Rodriguez AF, Nieves Valdes M. Health care expenditures and GDP in Latin American and OECD countries: a comparison using a panel cointegration approach. Int $\mathrm{J}$ Health Econ Manag. 2019;19:115-53.

39. Herrera-Añazco P, Amaya E, Atamari-Anahui N, Ccorahua-Rios M, Hernandez AV. Association between social determinants of health and trends in prevalence of hypertension in patients of the Peruvian Ministry of Health. Trop Med Int Health. 2019;24: 1434-41. https://doi.org/10.1111/tmi.13318.

40. Segura Vega L, Agusti R, Ruiz E. La hipertensión arterial en el Perú según el estudio TORNASOL II. Rev Peru de Cardiolía. 2011;37:19-27.

41. Lerner AG, Bernabe-Ortiz A, Gilman RH, Smeeth L, Miranda JJ. The "rule of halves" does not apply in Peru: awareness, treatment, and control of hypertension and diabetes in rural, urban, and ruralto-urban migrants. Crit Pathw Cardiol. 2013;12:53-8.

42. Villarreal-Zegarra D, Bernabe-Ortiz A. Association between arterial hypertension and depressive symptoms: Results from population-based surveys in Peru. Asia-Pac Psychiatry. 2020;12: e12385.

43. Li Z, Liu X, Zhang Z, Huang L, Zhong Q, He R, et al. Epidemiology of hypertension in a typical state-level poverty-stricken county in China and evaluation of a whole population health prevention project intervention. Int J Hypertens. 2019;2019:4634823.

44. Maslakpak MH, Safaie M. A comparison between the effectiveness of short message service and reminder cards regarding medication adherence in patients with hypertension: a randomized controlled clinical trial. Int J Community-Based Nurs Midwifery. 2016;4:209-18. 